\title{
Developmental Changes in Genetic and Shared Environmental Contributions to Smoking Initiation and Subsequent Smoking Quantity in Adolescence and Young Adulthood
}

\author{
Cristina B. Bares, ${ }^{1}$ Kenneth S. Kendler, ${ }^{2,3}$ and Hermine H. Maes ${ }^{2,3,4}$ \\ ${ }^{1}$ School of Social Work, Virginia Commonwealth University, Richmond, VA, USA \\ ${ }^{2}$ Department of Psychiatry, Virginia Commonwealth University, Richmond, VA, USA \\ ${ }^{3}$ Department of Human \& Molecular Genetics, Virginia Commonwealth University, Richmond, VA, USA \\ ${ }^{4}$ Massey Cancer Center, Virginia Commonwealth University, Richmond, VA, USA
}

\begin{abstract}
Background: Few studies examining the genetic architecture of cigarette smoking have focused on adolescents or examined developmental changes in additive genetic, shared environment, and unique environmental influences on liability to initiate cigarette smoking and quantity of cigarettes smoked. The aim of this study was to add to the literature on liability to initiate and use cigarettes during adolescence using a nationally representative sample. Method: Data for this study came from adolescent and young adult twin pairs (aged 14-33 years) from the National Longitudinal Study of Adolescent to Adult Health. We ran a series of developmental causal-contingent-common pathway models to examine whether additive genetic, shared, and unique environmental influences on liability to the initiation of cigarette use are shared with those on smoking quantity, and whether their contributions change across development. Results: We found evidence for a developmental shift in genetic and shared environmental contributions to cigarette use. Early in adolescence, genetic and environmental influences work independently on liability to cigarette smoking initiation and quantity of cigarettes smoked, but liability to these behaviors becomes correlated as individuals age into young adulthood. Conclusions: These findings provide insight into the causal processes underlying the liability to smoke cigarettes. With age, there is greater overlap in the genetic and environmental factors that influence the initiation of cigarette smoking and quantity of cigarettes smoked.
\end{abstract}

Keywords: adolescents, development, genetic influences, environmental influences, cigarette smoking

Tobacco use during adolescence continues to be a serious public health concern associated with increased mortality and personal and public costs (Substance Abuse and Mental Health Services Administration [SAMHSA], 2009). Adolescence is a critical period for the onset of cigarette use, regular cigarette use (SAMHSA, 2007), nicotine dependence (US Department of Health and Human Services, 1994), and a risk factor for the development of smoking-related illnesses (Heron et al., 2011) and other drug-related problems. Previous reviews of adult twin studies have found that additive genetic, shared and, unique environmental influences all play a role in smoking initiation (Li et al., 2003; Sullivan \& Kendler, 1999), but primarily additive and unique environmental influences influence smoking progression (i.e., developing symptoms of nicotine dependence; Kendler et al., 1999b; Neale et al., 2006). When smoking progression is op- erationalized as number of cigarettes smoked, then a small effect of the shared environment is found for adults ( $\mathrm{Li}$ et al., 2003). Other works have found that there is an overlap in the genetic contribution to smoking initiation, regular tobacco use, and nicotine dependence (Maes et al., 2004; Morley et al., 2007; Oncel et al., 2014), suggesting that some of the genetic factors that influence whether individuals initiate smoking also have an impact on how many cigarettes they subsequently smoke. In addition, studies of adult twins have

RECEIVED 13 February 2015; ACCEPTED 25 June 2015. First published online 31 July 2015.

ADDRESS FOR CORRESPONDENCE: Cristina B. Bares, School of Social Work, Virginia Commonwealth University, 1000 Floyd Ave., Richmond, VA 23284, USA. E-mail: cbares@vcu.edu 


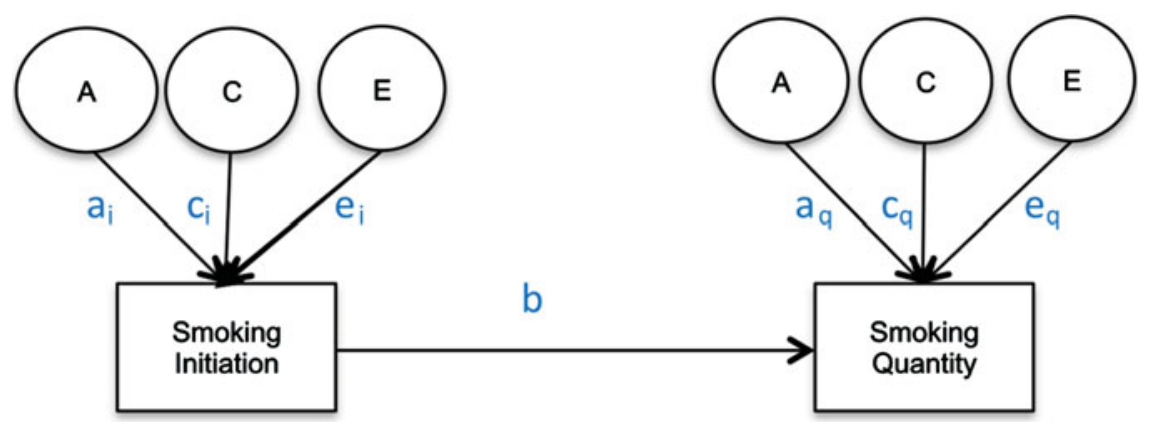

FIGURE 1

(Colour online) Causal-contingent-common pathway model.

shown that additive genetic factors influence age at smoking initiation, but a different set of genetic factors contribute to the number of cigarettes smoked (Broms et al., 2006).

Work with adolescent and young adult twins has suggested that smoking initiation is primarily influenced by shared environmental factors early in adolescence (Dick et al., 2006; Unger et al., 2011), although some studies do suggest that additive genetic effects play a role in having ever smoked a cigarette (Huizink et al., 2010; Kendler et al., 1993; Maes et al., 1999). As adolescents reach late adolescence and young adulthood, additive genetic factors become increasingly more important (Kendler et al., 2008; Koopmans et al., 1997; Maes \& Neale, 2009; Maes et al., 2004).

Due to the conditional nature of drug use (Kendler et al., 1999b), properly estimating the heritability of smoking quantity requires employing a conditional model that takes into account the heritability of cigarette smoking initiation. The appropriate method to examine additive genetic and shared environmental factors to liability of drug use quantity is a causal-contingent-common (CCC) pathway model (Kendler et al., 1999a) that allows for the concurrent estimation of quantity conditional on drug use initiation as well as for estimating the relationship between drug use initiation and drug use quantity (see Figure 1). The CCC model estimates separate liabilities for drug use initiation and for quantity of drug use given initiation. Once adolescents initiate smoking, previous studies have found that heaviness of smoking (light, moderate, or heavy cigarette use; Huizink et al., 2010; Koopmans et al., 1999) and the presence of nicotine dependence as measured by the Fagerstrom Test for Nicotine Dependence (Haberstick et al., 2007; Heatherton et al., 1991; Vink et al., 2005) are influenced by genetic factors, but no significant shared environmental effects have been reported. In a study of 11- to 19-year-old twins, the same additive genetic and shared environmental factors that influenced initiation of cigarette use were found to contribute to the variance in the number of cigarettes smoked (Fowler et al., 2007). The present study extends previous research in this area (Do et al., 2015; Oncel et al., 2014) by characterizing in greater detail the developmental changes in the heritability of the quantity of cigarettes smoked per day conditional on cigarette use initiation across different age groups spanning adolescence and young adulthood and testing for age-specific sex differences among twins from a nationally representative US sample.

\section{Material and Methods}

\section{Sample}

Data for this study came from twin pairs available in the National Longitudinal Study of Adolescent to Adult Health (Add Health; Harris et al., 2006, 2013). The Add Health study recruited adolescent participants when they were enrolled in high school and subsequently assessed them through three in-home interviews, for four waves of longitudinal data. In the first wave, participants' age ranged from 12 to 17 years and in the last wave, participants ranged in age from 28 to 33 years. At each wave of the four-wave longitudinal study, participants reported on whether they had ever smoked a cigarette, and if they indicated they had smoked, they were subsequently asked how many cigarettes they had smoked per day in the previous 30 days.

Zygosity of the twin pairs was determined by matching on 12 molecular genetic markers and through self-report questions regarding the twins' similarity (Harris et al., 2006). For this study, participants were divided into five groups based on sex and zygosity (monozygotic males (MZM), monozygotic females (MZF), dizygotic males (DZM), dizygotic females (DZF), and opposite sex dizygotic twins (DZO) so that we could test for qualitative and quantitative sex differences in the sources of genetic and environmental influences on the phenotypes.

In the Add Health study, data were available for 740 twin pairs aged 12 to 33 years. At younger ages (12 and 13 years), the prevalence of smoking was very low and no participants smoked more than 11 cigarettes per day, so data for this age group was not used. Beginning with age 14, we collapsed across ages resulting in having an age group of adolescent twins who were between 14 and 15 years of age ( $n=571$ individuals), a group of 16- to 17-year- 
TABLE 1

Demographic Characteristics by Age Group

\begin{tabular}{|c|c|c|c|c|c|}
\hline & \multicolumn{5}{|c|}{ Age groups (years) } \\
\hline & $\begin{array}{l}12-13 \\
(n=100)^{*}\end{array}$ & $\begin{array}{l}14-15 \\
(n=571)^{*}\end{array}$ & $\begin{array}{l}16-17 \\
(n=776)^{*}\end{array}$ & $\begin{array}{l}18-25 \\
(n=1,329)^{*}\end{array}$ & $\begin{array}{l}26+ \\
(n=1,308)\end{array}$ \\
\hline Mean age (SD) & $13(0)$ & $14.7(0.46)$ & $16.6(0.49)$ & $21.7(1.76)$ & $29.0(1.64)$ \\
\hline$M Z(\%)$ & 24.0 & 34.3 & 37.5 & 37.7 & 36.7 \\
\hline Female (\%) & 42.0 & 51.6 & 49.9 & 50.9 & 51.5 \\
\hline \multicolumn{6}{|l|}{ Ever smoking } \\
\hline Total sample (\%) & 39.0 & 53.8 & 70.4 & 76.4 & 76.2 \\
\hline Males (\%) & 41.4 & 55.4 & 73.8 & 80.4 & 81.1 \\
\hline Females (\%) & 35.7 & 52.2 & 66.9 & 72.5 & 71.7 \\
\hline \multicolumn{6}{|c|}{ Categorical quantity smoked - none } \\
\hline Total sample (\%) & 69.2 & 64.2 & 68.0 & 74.1 & 74.4 \\
\hline Males (\%) & 70.8 & 58.8 & 62.0 & 71.4 & 72.8 \\
\hline Females (\%) & 66.7 & 69.5 & 74.5 & 76.9 & 76.2 \\
\hline \multicolumn{6}{|c|}{ Categorical quantity smoked - light: 1-10 CPD } \\
\hline Total sample (\%) & 30.8 & 29.6 & 18.0 & 17.0 & 16.9 \\
\hline Males (\%) & 29.2 & 31.4 & 18.8 & 16.4 & 16.0 \\
\hline Females (\%) & 33.3 & 27.9 & 17.0 & 17.8 & 17.8 \\
\hline \multicolumn{6}{|c|}{ Categorical quantity smoked - heavy: $11+$ CPD } \\
\hline Total sample (\%) & No obs & 6.2 & 14.1 & 8.9 & 8.7 \\
\hline Males (\%) & No obs & 9.8 & 19.2 & 12.2 & 11.3 \\
\hline Females (\%) & No obs & 2.6 & 8.5 & 5.3 & 6.0 \\
\hline
\end{tabular}

Note: ${ }^{*} n$ : number of individuals; obs: observations.

\section{TABLE 2}

Tetrachoric Correlations for Cigarette Use Initiation (95\% CI) by Sex, Zygosity, and Age Group

\begin{tabular}{lllllll}
\hline & \multicolumn{2}{c}{ Females } & & \multicolumn{2}{c}{ Males } & \\
\cline { 2 - 3 } \cline { 5 - 6 } & $\mathrm{MZ}$ & $\mathrm{DZ}$ & & $\mathrm{MZ}$ & $\mathrm{DZ}$ & $\mathrm{DZO}$ \\
\hline 14- to 15-year olds & 0.91 & 0.88 & & 0.85 & 0.72 & 0.38 \\
(n= 287 twin pairs) & $(0.85,0.97)$ & $(0.81,0.95)$ & & $(0.75,0.94)$ & $(0.59,0.85)$ & $(0.21,0.55)$ \\
16- to 17-year olds & 0.64 & 0.63 & & 0.82 & 0.57 & 0.55 \\
(n= 389 twin pairs) & $(0.50,0.79)$ & $(0.50,0.76)$ & & $(0.73,0.91)$ & $(0.40,0.74)$ & $(0.42,0.69)$ \\
18- to 25-year olds & 0.83 & 0.41 & & 0.88 & 0.34 & 0.16 \\
(n=709 twin pairs) & $(0.76,0.90)$ & $(0.27,0.55)$ & & $(0.82,0.94)$ & $(0.17,0.51)$ & $(0.01,0.31)$ \\
26- to 33-year olds & 0.87 & 0.41 & & 0.87 & 0.51 & 0.03 \\
(n=723 twin pairs) & $(0.81,0.93)$ & $(0.28,0.55)$ & $(0.81,0.94)$ & $(0.36,0.67)$ & $(-0.15,0.22)$ \\
\hline
\end{tabular}

old participants ( $n=776$ individuals), a group of 18 - to 25 -year-old participants ( $n=1,329$ individuals), and a group of participants who were aged 26-33 years $(n=$ 1,308 individuals). Table 1 presents demographic information, the prevalence of having ever smoked a cigarette, and the percentage of individuals in each of the three categories of cigarette smoking quantity for each age group. Tetrachoric and polychoric correlations for cigarette smoking initiation and cigarette smoking quantity are available in Tables 2 and 3 respectively.

\section{Measures}

The aim of this study was to examine developmental changes in the etiology of smoking cigarettes, so cigarette smoking initiation and cigarette smoking quantity variables were created for each available age in the Add Health data. The smoking initiation variable was coded 1 when participants responded yes, or 0 when the answer was no to the survey question: 'Have you ever smoked a cigarette?' Subsequently, those participants who answered yes to having initiated smoking were asked how many cigarettes they had smoked in the previous 30 days. The answer to this question was used to create the smoking quantity variable. In Wave 3 of the Add Health data, the options available to participants to respond to the question about how many cigarettes they had smoked in the previous 30 days were ordinal categories rather than open-ended, as in waves 1,2 , and 4 . Therefore, the quantity smoked variable used in the present analyses was an ordered categorical variable such that ' 0 ' referred to not having smoked any cigarettes in the previous 30 days, ' 1 ' referred to smoking between 1 and 11 cigarettes per day, and '2' indicated smoking more than 11 cigarettes per day. Further, those participants who reported not having ever smoked a cigarette (the never smokers) were coded as having missing information for the smoking quantity variable as has been suggested by Neale and colleagues (2006).

\section{Analysis Plan}

Behavioral genetic studies are designed to uncover the sources of individual differences that give rise to variations 
in a phenotype and take advantage of the differences in the proportion of segregating genes between pairs of monozygotic (MZ) and dizygotic (DZ) twins who are reared together. MZ twins share $100 \%$ of their segregating genes, while DZ twins share on average $50 \%$ of their genes. If genetic factors contribute to a phenotype then MZ twins would be expected to be more similar than DZ twins. The variance in a phenotype is partitioned into additive genetic (A), shared environmental (C), or unique environmental (E) sources, where additive genetic sources of variance involve the cumulative effects of individual genes on a phenotype. Shared environmental sources are aspects of the environment that both twins experience and increase their similarity. Non-shared environmental sources of variance are aspects of the environment that contribute to making twins different in the same family. Measurement error is also contained in the non-shared environmental component.

The first step in data analysis involved testing the assumptions that the thresholds for cigarette smoking initiation were equal across twin order, sex, and zygosity for each age group. Then univariate analyses for binary variables decomposed the variance of cigarette smoking initiation into additive genetic (A), shared environmental (C), and unique environmental (E) sources and tested sex differences. Two types of sex differences were tested for: differences in the magnitude of genetic effects between males and females (quantitative sex differences) as well as differences due to a different set of genes influencing the phenotype in males than in females (qualitative sex differences). Quantitative and qualitative sex differences in cigarette smoking initiation were tested by comparing the likelihood statistic (-2LL) produced by reduced models with the likelihood of the full model. The difference in likelihood between the two models is known as the likelihood ratio test and is asymptotically distributed as $\chi^{2}$.

Causal-contingent-common analyses. Age-specific CCC models (Kendler et al., 1999a; Maes et al., 2004) for ordered categorical variables were run, starting with a full, sex-specific model where the three sources (A, C, E) of variance were included for both cigarette smoking initiation and cigarette quantity smoked, and included a common pathway between initiation and quantity (Model 1). First, an overall test for sex differences was performed (Model 2), followed by an overall test for the significance of genetic factors for both smoking initiation $\left(a_{i}\right.$ in Figure 1$)$ and smoking quantity $\left(\mathrm{a}_{\mathrm{q}}\right.$ in Figure 1$)$ at once (Model 3 ), and shared environmental contributions to smoking initiation and smoking quantity simultaneously (Model 4). The significance of the common pathway between smoking initiation and quantity smoked (b in Figure 1) was tested at each age group (Model 5). A common pathway coefficient of 0 would indicate that smoking initiation and quantity smoked are independent processes for that particular age group, while a common pathway coefficient of 1 would in- dicate that smoking quantity is on the same continuum as smoking initiation. The statistical significance of the variance components for smoking initiation $\left(a_{i}\right.$ and $c_{i}$ in Figure 1) and for smoking quantity $\left(\mathrm{a}_{\mathrm{q}}\right.$ and $\mathrm{c}_{\mathrm{q}}$ in Figure 1$)$ was tested separately by fixing each to zero and examining model fit (Models 6-9). Analyses were done in R (RCore, 2012) using the OpenMx package (Boker et al., 2011).

\section{Results}

Prevalence of lifetime cigarette use by age group is presented in Table 1. The prevalence rates for this sample are in line with the national estimates available for the years during which the survey was carried out (Johnston et al., 2013). Slightly over half of the 14 - to 15 -year olds, $70 \%$ of the 16 - to 17 -year olds, and over three-quarters of both the 18- to 25 year olds and 26- to 33-year olds had ever smoked a cigarette. Of the 14- to 15-year olds who had ever smoked, $29.6 \%$ were light smokers, and $6.2 \%$ were heavy smokers. The proportion of heavy smokers was highest in the 16- to 17year olds (14.1\%) and lowest in the 26- to 33-year old group $(8.7 \%)$. Table 1 presents the prevalence of lifetime cigarette use and quantity of cigarettes smoked by sex and zygosity.

\section{Age-Specific Univariate Models of Smoking Initiation}

For each age group, we first fitted a saturated model, where the thresholds and correlations for cigarette smoking initiation were allowed to vary by twin order, sex, and zygosity. Then twin model assumptions were tested by evaluating changes in model fit when the thresholds were constrained across twin order, zygosity, same- and opposite-sex twins, and for males and females (results available upon request). Thresholds could be equated across twin order, zygosity (except at young adulthood), same- and opposite sex, and males and females (except in the oldest age group). Next, whether different genetic factors or environmental influences in males and females contribute to the variance in cigarette smoking initiation (qualitative sex differences), as well as whether males and females differed in the magnitude of additive genetic effects (quantitative sex differences), were tested for at each age group. There was no evidence of qualitative or quantitative sex differences in cigarette smoking initiation at any of the age groups (results available upon request).

\section{Age-Specific Causal-Contingent-Common Pathway Models}

For the 14- to 15-year-old group, the full CCC pathway model allowed the loadings of variance components for cigarette smoking initiation and quantity of cigarettes smoked to be freely estimated across sexes (Table 4, Model 1). Constraining the parameters to be equal across sexes did not cause the fit of the model to deteriorate (Model 2: $\chi^{2}=$ $7.52, d f=9, p=.583$, see Table 3). Next, we tested the overall significance of the shared environment or the genetic 
TABLE 3

Polychoric Correlations for Cigarette Quantity ( $95 \%$ Cl) by Sex, Zygosity, and Age Group

\begin{tabular}{|c|c|c|c|c|c|}
\hline & \multicolumn{2}{|c|}{ Females } & \multicolumn{2}{|c|}{ Males } & \multirow[b]{2}{*}{ DZO } \\
\hline & $\mathrm{MZ}$ & DZ & $M Z$ & DZ & \\
\hline 14- to 15 -year olds & 0.47 & -0.23 & -0.17 & 0.04 & 0.61 \\
\hline ( $n=287$ twin pairs) & $(0.23,0.71)$ & $(-0.54,0.08)$ & $(-0.50,0.15)$ & $(-0.21,0.29)$ & $(0.42,0.81)$ \\
\hline 16-17-year olds & 0.76 & 0.47 & 0.33 & 0.26 & 0.55 \\
\hline ( $n=389$ twin pairs) & $(0.63,0.88)$ & $(0.26,0.68)$ & $(0.13,0.54)$ & $(0.07,0.45)$ & $(0.40,0.70)$ \\
\hline 18 - to 25 -year olds & 0.61 & 0.24 & 0.55 & 0.08 & 0.24 \\
\hline ( $n=709$ twin pairs) & $(0.49,0.73)$ & $(0.04,0.44)$ & $(0.42,0.68)$ & $(-0.10,0.25)$ & $(0.07,0.40)$ \\
\hline 26- to 33-year olds & 0.59 & 0.00 & 0.69 & 0.00 & 0.18 \\
\hline ( $n=723$ twin pairs) & $(0.46,0.72)$ & $(-0.23,0.23)$ & $(0.57,0.80)$ & $(-0.18,0.17)$ & $(0.11,0.25)$ \\
\hline
\end{tabular}

TABLE 4

Causal-Contingent-Common Pathway Model Comparison by Age Group

\begin{tabular}{|c|c|c|c|c|c|c|c|c|}
\hline Age group & Model & Parameters & $-2 \mathrm{LL}$ & $d f$ & AIC & $\Delta \mathrm{LL}$ & $\Delta d f$ & $p$ \\
\hline \multirow[t]{9}{*}{$14-15$} & 1. $C C C-A C E$ & 22 & 1181.22 & 860 & -538.78 & - & - & - \\
\hline & 2. $C C C-A C E$ no sex differences & 13 & 1188.75 & 869 & -549.25 & 7.52 & 9 & .583 \\
\hline & 3. $\mathrm{CCC}-\mathrm{AE}$ & 11 & 1195.62 & 871 & -546.38 & 6.87 & 2 & .032 \\
\hline & 4. $\mathrm{CCC}-\mathrm{CE}$ & 11 & 1193.47 & 871 & -548.53 & 4.72 & 2 & .094 \\
\hline & 5. Independent & 12 & 1191.29 & 870 & -548.71 & 2.54 & 1 & .111 \\
\hline & 6. $C C C-$ Drop initiation A & 11 & 1195.87 & 871 & -546.13 & 4.58 & 1 & .032 \\
\hline & 7. CCC - Drop quantity A & 11 & 1191.29 & 871 & -550.71 & 0.00 & 1 & 1.000 \\
\hline & 8. CCC - Drop initiation C & 11 & 1197.44 & 871 & -544.56 & 6.15 & 1 & .013 \\
\hline & 9. CCC - Drop quantity C & 11 & 1191.63 & 871 & -550.37 & 0.34 & 1 & .560 \\
\hline \multirow[t]{9}{*}{$16-17$} & 1. $\mathrm{CCC}-\mathrm{ACE}$ & 22 & 1734.41 & 1304 & -873.59 & - & - & - \\
\hline & 2. $C C C-A C E$ no sex differences & 13 & 1741.91 & 1313 & -884.09 & 7.50 & 9 & .585 \\
\hline & 3. $C C C-A E$ & 11 & 1749.23 & 1315 & -880.77 & 7.32 & 2 & .026 \\
\hline & 4. $\mathrm{CCC}-\mathrm{CE}$ & 11 & 1747.42 & 1315 & -882.58 & 5.51 & 2 & .063 \\
\hline & 5. Independent & 12 & 1761.75 & 1314 & -866.25 & 19.84 & 1 & .000 \\
\hline & 6. $C C C$ - Drop initiation A & 12 & 1747.20 & 1314 & -880.80 & 5.29 & 1 & .021 \\
\hline & 7. CCC - Drop quantity A & 12 & 1743.15 & 1314 & -884.85 & 1.25 & 1 & .264 \\
\hline & 8. CCC - Drop initiation C & 12 & 1748.11 & 1314 & -879.89 & 6.21 & 1 & .013 \\
\hline & 9. CCC - Drop quantity C & 12 & 1742.68 & 1314 & -885.32 & 0.78 & 1 & .379 \\
\hline \multirow[t]{9}{*}{$18-25$} & 1. $C C C-A C E$ & 22 & 2803.21 & 2326 & -1848.79 & - & - & - \\
\hline & 2. $C C C-A C E$ no sex differences & 13 & 2816.48 & 2335 & -1853.52 & 13.27 & 9 & .151 \\
\hline & 3. $C C C-A E$ & 11 & 2816.48 & 2337 & -1857.521 & 0.00 & 2 & 1.000 \\
\hline & 4. $C C C-C E$ & 11 & 2854.90 & 2337 & -1819.101 & 38.42 & 2 & .000 \\
\hline & 5. Independent & 12 & 2825.35 & 2336 & -1846.653 & 8.87 & 1 & .003 \\
\hline & 6. CCC - Drop initiation A & 12 & 3350.42 & 2336 & -1321.581 & 533.94 & 1 & .000 \\
\hline & 7. CCC - Drop quantity A & 12 & 2819.10 & 2336 & -1852.904 & 2.62 & 1 & .106 \\
\hline & 8. CCC - Drop initiation C & 12 & 2816.48 & 2336 & -1855.521 & 0.00 & 1 & 1.000 \\
\hline & 9. CCC - Drop quantity C & 12 & 2816.48 & 2336 & -1855.521 & 0.00 & 1 & 1.000 \\
\hline \multirow[t]{9}{*}{$26-33$} & 1. $\mathrm{CCC}-\mathrm{ACE}$ & 22 & 2746.08 & 2287 & -1827.92 & - & - & - \\
\hline & 2. $C C C-A C E$ no sex differences & 13 & 2757.19 & 2296 & -1834.81 & 11.10 & 9 & .269 \\
\hline & 3. $C C C-A E$ & 11 & 2757.19 & 2298 & -1838.81 & 0.00 & 2 & 1.000 \\
\hline & 4. $\mathrm{CCC}-\mathrm{CE}$ & 11 & 3033.37 & 2298 & -1562.631 & 276.18 & 2 & .000 \\
\hline & 5. Independent & 12 & 2767.72 & 2297 & -1826.281 & 10.53 & 1 & .001 \\
\hline & 6. CCC - Drop initiation A & 12 & 2788.61 & 2297 & -1805.393 & 31.42 & 1 & .000 \\
\hline & 7. CCC - Drop quantity A & 12 & 2760.25 & 2297 & -1833.752 & 3.06 & 1 & .080 \\
\hline & 8. CCC - Drop initiation C & 12 & 2757.19 & 2297 & -1836.81 & 0.00 & 1 & 1.000 \\
\hline & 9. CCC - Drop quantity C & 12 & 2757.19 & 2297 & -1836.81 & 0.00 & 1 & 1.000 \\
\hline
\end{tabular}

contribution to liability of smoking initiation and smoking quantity, and found that excluding the shared environment significantly worsened the fit of the model (Model 3: $\left.\chi^{2}=6.87, d f=2, p=.032\right)$ but not when dropping the influence of additive genetic factors (Model $4: \chi^{2}=4.72$, $d f=2, p=.094)$. We then tested the significance of the beta coefficient between smoking initiation and smoking quantity and found that the common pathway in this age group was not significant (Model 5: $\chi^{2}=2.54, d f=1$, $p=.111)$. Subsequent models for this age group did not include the common pathway between smoking initiation and smoking quantity. We then tested the significance of the additive genetic contribution to smoking initiation (Model 6) and smoking quantity (Model 7) and that of the shared environment on smoking initiation (Model 8) and smoking quantity (Model 9). We found that additive genetic and 
shared environmental influences were significant for smoking initiation (Model 6: $\chi^{2}=4.58, d f=1, p=.032$ and Model 8: $\left.\chi^{2}=6.15, d f=1, p=.013\right)$ but not for smoking quantity (Model 7: $\chi^{2}=0.0, d f=1, p=1.000$ and Model 9: $\left.\chi^{2}=0.34, d f=1, p=.56\right)$.

For the 16- to 17-year-old group, constraining the variance components and the common pathway between cigarette smoking initiation to quantity of cigarettes smoked to be equal across males and females did not worsen model fit $\left(\chi^{2}=7.50, d f=9, p=.585\right)$. Removing the effects of the shared environment (Model 3: $\chi^{2}=7.32, d f=2, p=.026$ ) caused a significant reduction in the fit of the model but not when additive genetic effects were removed (Model $4: \chi^{2}=$ 5.51, $d f=2, p=.063)$. The significance of the common pathway between cigarette smoking initiation and quantity of cigarettes smoked was tested by setting it to zero and resulted in worse model fit (Model 5: $\chi^{2}=19.84, d f=1, p<$ .0001 ), suggesting that for the 16- to 17-year-old group, the liabilities to smoking initiation and smoking quantity were correlated. Dropping either additive genetic effects from smoking initiation (Model 6: $\chi^{2}=5.29, d f=1, p=.021$ ) or shared environmental contributions to smoking initiation (Model 8: $\chi^{2}=6.21, d f=1, p=.013$ ) worsened the fit of the model, but removing the influence of additive genetic effects (Model 7: $\chi^{2}=1.25, d f=1, p=.264$ ) or shared environmental influences from smoking quantity (Model 9: $\left.\chi^{2}=0.78, d f=1, p=.379\right)$ did not.

For the 18- to 25 -year olds, testing a model where the estimates in the parameters were equated across males and females resulted in no significant reduction in model fit (Model 2: $\chi^{2}=13.27, d f=9, p=.151$ ), so the subsequent models contained equal $\mathrm{A}, \mathrm{C}$, and $\mathrm{E}$ estimates and the common pathway across sex. Next, a model that tested the overall contribution of the shared environment was not significant (Model 3: $\chi^{2}=0.0, d f=2, p=$ $1.0)$, but that of additive genetic effects was significant (Model 4: $\chi^{2}=38.42, d f=2, p<.001$ ). Next, whether the liabilities to smoking initiation and smoking quantity were independent of one another was tested by removing the common pathway from the model and resulted in a worse fit (Model 5: $\chi^{2}=8.87, d f=1, p$ $<.01)$. In subsequent models for this age group, the common pathway was included. The specific influence of additive genetic effects was found to be important for smoking initiation (Model 6: $\chi^{2}=534.23, d f=1, p$ $<.001$ ) but not for smoking quantity (Model 7: $\chi^{2}=$ 2.62, $d f=1, p=.106)$. The influence of the shared environment did not deteriorate model fit on liability to smoking initiation (Model 8: $\chi^{2}=0.0, d f=1, p=$ 1.0), or smoking quantity (Model 9: $\chi^{2}=0.0, d f=1$, $p=1.0)$.

Lastly, for the 26- to 33-year-old age group, equating the estimates across sex did not result in worse model fit (Model 2: $\chi^{2}=11.1, d f=9, p=.269$ ), suggesting that for this age group there were no significant differences by sex in the estimates for A, C, and E or in the beta coefficient of the common pathway. Removing the overall influence of the shared environment did not cause a reduction in model fit (Model 3: $\chi^{2}=0.0, d f=2, p=1.0$ ), but the removal of additive genetic influences did cause the model to fit worse (Model 4: $\chi^{2}=276.18, d f=2, p<.001$ ). When the common pathway between smoking initiation and smoking quantity was removed in Model 5, the model fit worsened $\left(\chi^{2}=10.53, d f=1, p<.01\right)$, suggesting that the liabilities to smoking initiation and smoking quantity are correlated at this age. Additive genetic influences were important for smoking initiation (Model 6: $\chi^{2}=460.24, d f=1, p<$ .001 ) but not for smoking quantity (Model $7: \chi^{2}=3.06$, $d f=1, p=.08)$. The influence of shared environment was not significant for smoking initiation or smoking quantity (Model 8: $\chi^{2}=0.0, d f=1, p=1.0$; Model 9: $\chi^{2}=0.0, d f=$ $1, p=1.0)$.

The variance component estimates and associated $95 \%$ confidence intervals (CI) from the CCC pathway model without sex differences are presented in Table 5 for each age group. The influence of risk factors for quantity of cigarettes smoked that exert their influence through their effect on smoking initiation was found to increase through adolescence and into young adulthood. For the 14- to 15-year-old age group, we found that risk factors influencing smoking initiation were independent of those that contributed to smoking quantity. In the three older age groups, the risk factors predisposing to smoking initiation were correlated with those that influence smoking quantity $(98 \%, 62 \%$, and $65 \%$, respectively) suggesting substantial overlap in the factors that influence initiating cigarette use and the number of cigarettes smoked among older adolescents and young adults.

We present estimates of the variance components for the same model across all age groups (Table 5), even though the causal path was not significant for age group 14-15 and some of the genetic and shared environmental contributions were not significant. We estimated that for the 14- to 15 -year-old age group, $42 \%$ of the variance in liability to smoking initiation was accounted for by additive genetic factors, $46 \%$ by shared environmental factors, and $12 \%$ by non-shared environmental factors. Only non-shared environmental factors accounted for a significant portion of the variance $(63 \%)$ in quantity of cigarettes smoked. In the 16 - to 17 -year-olds, $43 \%$ of the variance in liability to smoking initiation was accounted for by additive genetic factors, $10 \%$ was attributable to the shared environment, and $26 \%$ by non-shared environment. The additive genetic and shared environmental influences on smoking initiation were found to be almost completely shared with those that influence smoking quantity (causal path estimated at 0.93 ) but no additional genetic effects or shared environmental effects were found for this age group to influence the quantity of cigarettes smoked. The estimates for the 18- to 25-year-old and the 26- to 33-year-old age groups 
TABLE 5

Parameter Estimates $(95 \% \mathrm{Cl})$ From CCC Pathway No Sex Differences Model

\begin{tabular}{|c|c|c|c|c|c|c|c|c|c|c|}
\hline \multirow[b]{2}{*}{ Age group } & \multicolumn{3}{|c|}{ Smoking initiation } & \multirow[b]{2}{*}{ Beta } & \multicolumn{3}{|c|}{ Smoking quantity } & \multicolumn{3}{|c|}{ Total } \\
\hline & $a^{2}$ & $c^{2}$ & $e^{2}$ & & $a^{2} s$ & $c^{2} s$ & $e^{2} s$ & $a^{2} t$ & $c^{2} t$ & $e^{2} t$ \\
\hline 14- to 15 -year olds & $\begin{array}{l}0.42 \\
(0.04,0.80)\end{array}$ & $\begin{array}{l}0.46 \\
(0.12,0.75)\end{array}$ & $\begin{array}{l}0.12 \\
(0.04,0.26)\end{array}$ & $\begin{array}{c}0.52 \\
(-0.16,0.82)\end{array}$ & $\begin{array}{l}0.00 \\
(0.00,0.00)\end{array}$ & $\begin{array}{l}0.10 \\
(0.00,0.38)\end{array}$ & $\begin{array}{l}0.63 \\
(0.30,0.98)\end{array}$ & 0.11 & 0.23 & 0.66 \\
\hline 16- to 17 -year olds & $\begin{array}{l}0.43 \\
(0.41,0.76)\end{array}$ & $\begin{array}{l}0.10 \\
(0.05,0.28)\end{array}$ & $\begin{array}{l}0.26 \\
(0.13,0.27)\end{array}$ & $\begin{array}{l}0.93 \\
(0.92,0.95)\end{array}$ & $\begin{array}{l}0.00 \\
(0.00,0.13)\end{array}$ & $\begin{array}{l}0.00 \\
(0.00,0.00)\end{array}$ & $\begin{array}{l}0.10 \\
(0.05,0.28)\end{array}$ & 0.37 & 0.09 & 0.32 \\
\hline 18- to 25 -year olds & $\begin{array}{l}0.84 \\
(0.73,0.92)\end{array}$ & $\begin{array}{l}0.00 \\
(0.00,0.00)\end{array}$ & $\begin{array}{l}0.16 \\
(0.08,0.27)\end{array}$ & $\begin{array}{l}0.62 \\
(0.26,0.78)\end{array}$ & $\begin{array}{l}0.30 \\
(0.02,0.57)\end{array}$ & $\begin{array}{l}0.00 \\
(0.00,0.00)\end{array}$ & $\begin{array}{l}0.32 \\
(0.13,0.53)\end{array}$ & 0.62 & 0.00 & 0.38 \\
\hline 26- to 33-year olds & $\begin{array}{l}0.87 \\
(0.76,0.93)\end{array}$ & $\begin{array}{l}0.00 \\
(0.00,0.00)\end{array}$ & $\begin{array}{l}0.13 \\
(0.07,0.24)\end{array}$ & $\begin{array}{l}0.65 \\
(0.32,0.80)\end{array}$ & $\begin{array}{l}0.27 \\
(0.01,0.54)\end{array}$ & $\begin{array}{l}0.00 \\
(0.00,0.00)\end{array}$ & $\begin{array}{l}0.31 \\
(0.12,0.52)\end{array}$ & 0.63 & 0.00 & 0.37 \\
\hline
\end{tabular}

indicated that only additive genetic factors accounted for familial resemblance in liability to smoking initiation $(84 \%$ and $87 \%$ respectively), and that these factors influenced smoking quantity through a substantial common path. Additional genetic effects were found to influence the quantity of cigarettes smoked for both young adult age groups (about $30 \%$ each).

\section{Discussion}

The aim of the present study was to examine developmental changes in the etiology of smoking behavior by modeling the influence of additive genetic and shared environmental influences of quantity of cigarettes smoked conditional on having initiated cigarette smoking. Consistent with previous work, the results of the present study did not find sex differences in the proportion of variance explained by genetic or environmental factors in adolescent smoking initiation or quantity of cigarettes smoked (Boomsma et al., 1994; McGue et al., 2000; Rende et al., 2005).

The results indicate the presence of developmental changes in the degree of overlap between the liability of smoking initiation and smoking quantity from adolescence and into young adulthood. The common pathway between liability to cigarette smoking initiation and cigarette smoking quantity could be dropped from the model in early adolescence, suggesting that different risk factors influence whether individuals have initiated cigarette use and how many cigarettes they subsequently smoked. For older adolescents and young adults, removing the common pathway between liability to initiate smoking and quantity smoked worsened model fit, suggesting the presence of correlated liabilities between cigarette use initiation and cigarette smoking quantity, as has been found in previous adult twin studies (Boomsma et al., 1994; Maes et al., 2004). Thus, with age, the factors that influence the initiation of smoking also play a role in how many cigarettes individuals smoke. At ages $16-17$, we found that $93 \%$ of the variance in liability to the amount of cigarette smoked was shared with the liability to initiate cigarette smoking. The corresponding proportions of variance in liability of cigarette smoking quantity shared with smoking initiation are $62 \%$ for the 18 - to 25 -year-old group, and $65 \%$ for the 26- to 33-year-old group. Recent reports of adolescent and young adult smoking have shown similar estimates for the proportion of variance in liability shared between smoking initiation and quantity (Do et al., 2015; Oncel et al., 2014).

Further, the findings suggest developmental changes in the factors that contribute to smoking initiation and number of cigarettes smoked when quantity smoked is modeled contingent on initiation. For the youngest age group, additive genetic and shared environmental factors were found to contribute to the liability of smoking initiation, but there were no new additive genetic or shared environmental influences specific to the liability of smoking quantity. Previous adolescent and young adult twin studies that have estimated the heritability of cigarettes smoked contingent on cigarette use initiation have included twins of a broader age range (Boomsma et al., 1994; Oncel et al., 2014) during a time when the etiology of smoking behavior is changing rapidly. The differences in the results observed in the present study compared with previous findings may be due to our age-specific focus, which uncovered a developmental change that may have been previously overlooked. Consistent with our findings, recently, Do and colleagues (2015) reported no evidence of new additive genetic effects on the quantity of cigarettes smoked in early adolescence. As individuals aged into late adolescence and young adulthood, the influence of additive genetic factors became more important for the initiation of cigarette use, a finding that is consistent with previous research (Do et al., 2015; Kendler et al., 2012; Koopmans et al., 1997). For the two oldest age groups (18-25 and 26-33), shared environmental influences did not contribute significantly to the liability to initiate smoking but additive genetic effects were significant.

We show that there are changes in the overlap of additive genetic and environmental factors that play a role in the initiation of smoking during early adolescence and into young adulthood. This finding adds to the literature on the developmental changes in the contributions of additive genetic and shared environmental factors on smoking initiation (Boomsma et al., 1994; Han et al., 1999) and smoking quantity and delineates the developmental shift from shared environmental influences on smoking initiation to 
additive genetic ones (Do et al., 2015; Koopmans et al., 1997; Oncel et al., 2014).

It has been known that smoking behaviors are complex behavioral traits that are under genetic and environmental influence (Kendler et al., 2012; Munafo et al., 2004). The present study adds to a growing body of literature (Do et al., 2015; Oncel et al., 2014) indicating that the genetic and environmental risk factors for smoking behaviors change over adolescence and into young adulthood. Efforts to find the gene clusters associated with cigarette use have resulted in identifying dopamine receptor genes associated with cigarette use initiation, progression into regular use, and nicotine dependence (Munafo et al., 2004). Further, once individuals begin using cigarettes and are exposed to nicotine, nicotinic acetylcholine receptor genes have been found to be associated with both the number of cigarettes smoked per day (Liu et al., 2010; Saccone et al., 2010; Tobacco \& Genetics Consortium, 2010) and nicotine dependence (Chen et al., 2009; Wang et al., 2014; Ware et al., 2011). However, this work has focused almost exclusively on adult samples. Whether the same genes are important for younger samples has yet to be determined. Our results indicate that during early adolescence, the shared environment plays a substantial role in cigarette use, thus characterizing how different environmental exposures interact with gene clusters in increasing risk for initiating and maintaining cigarette use during this age group will provide a comprehensive understanding of the unfolding of cigarette use. The implications of these findings for the future gene finding research suggest the need to search for genetic variants for cigarette use initiation and quantity that are developmentally specific.

\section{Limitations}

The findings of the present study should be considered with the following limitations in mind. First, to examine developmental changes, the sample of available twins in the data was divided into groups according to age, and this may have reduced the power to detect significant sex effects, especially at the youngest ages where the sample of twin pairs was 287. Second, to have a comparable quantity smoked variable across each assessment, we turned a continuous measure of cigarettes smoked per day into an ordinal variable, which may have resulted in loss of information to detect individual differences. Lastly, recent research has indicated important racial/ethnic differences in age of smoking onset (Clark et al., 2013), in quantity of cigarettes smoked (Gutman et al., 2011), and in the development of nicotine dependence (Duncan et al., 2012). In the present analyses, we did not test for the possibility that additive genetic influences on the liability to initiate smoking and on the quantity of cigarettes smoked would differ by racial/ethnic background.

\section{Acknowledgments}

The research reported in this publication was supported by the National Institute on Drug Abuse of the National Institutes of Health under award numbers R01DA025109 (H.H.M.) and K01DA036681 (C.B.B.). The content is solely the responsibility of the authors and does not necessarily represent the official views of the National Institutes of Health.

\section{References}

Boker, S., Neale, M., Maes, H., Wilde, M., Spiegel, M., Brick, T., ... Bates, T. (2011). OpenMx: An open source extended structural equation modeling framework. Psychometrika, 76, 306-317.

Boomsma, D. I., Koopmans, J. R., Doornen, L. J., \& Orlebeke, J. F. (1994). Genetic and social influences on starting to smoke: A study of Dutch adolescent twins and their parents. Addiction, 89, 219-226.

Broms, U., Silventoinen, K., Madden, P. A., Heath, A. C., \& Kaprio, J. (2006). Genetic architecture of smoking behavior: A study of Finnish adult twins. Twin Research and Human Genetics, 9, 64-72.

Chen, X., Chen, J., Williamson, V. S., An, S. S., Hettema, J. M., Aggen, S. H., ... Kendler, K. S. (2009). Variants in nicotinic acetylcholine receptors $\alpha 5$ and $\alpha 3$ increase risks to nicotine dependence. American Journal of Medical Genetics Part B: Neuropsychiatric Genetics, 150, 926-933.

Clark, T. T., Doyle, O., \& Clincy, A. (2013). Age of first cigarette, alcohol, and marijuana use among US biracial/ethnic youth: A population-based study. Addictive Behaviors, 38, 24502454.

Dick, D., Barman, S., \& Pitkänen, T. (2006). Genetic and environmental influences on the initiation and continuation of smoking and drinking. In L. Pulkkinen, J. Kaprio, \& J. Rose (Eds.), Socioemotional development and health from adolescence to adulthood (pp. 126-145). Cambridge, UK: Cambridge University Press.

Do, E. K., Prom-Wormley, E. C., Eaves, L. J., Silberg, J. L., Miles, D. R., \& Maes, H. H. (2015). genetic and environmental influences on smoking behavior across adolescence and young adulthood in the Virginia twin study of adolescent behavioral development and the transitions to substance abuse follow-up. Twin Research and Human Genetics, $18,43-51$.

Duncan, A. E., Lessov-Schlaggar, C. N., Sartor, C. E., \& Bucholz, K. K. (2012). Differences in time to onset of smoking and nicotine dependence by race/ethnicity in a Midwestern sample of adolescents and young adults from a high risk family study. Drug and Alcohol Dependence, 125, 140-145.

Fowler, T., Lifford, K., Shelton, K., Rice, F., Thapar, A., Neale, M. C., ... Van Den Bree, M. (2007). Exploring the relationship between genetic and environmental influences on initiation and progression of substance use. Addiction, 102, 413-422.

Gutman, L. M., Eccles, J. S., Peck, S., \& Malanchuk, O. (2011). The influence of family relations on trajectories of cigarette 
and alcohol use from early to late adolescence. Journal of Adolescence, 34, 119-128.

Haberstick, B. C., Timberlake, D., Ehringer, M. A., Lessem, J. M., Hopfer, C. J., Smolen, A., ... Hewitt, J. K. (2007). Genes, time to first cigarette and nicotine dependence in a general population sample of young adults. Addiction, 102, 655-665.

Han, C., McGue, M. K., \& Iacono, W. G. (1999). Lifetime tobacco, alcohol and other substance use in adolescent Minnesota twins: Univariate and multivariate behavioral genetic analyses. Addiction, 94, 981-993.

Harris, K. M., Halpern, C. T., Haberstick, B. C., \& Smolen, A. (2013). The National Longitudinal Study of Adolescent to Adult Health (Add Health) sibling pairs data. Twin Research and Human Genetics, 16, 391-398.

Harris, K. M., Halpern, C. T., Smolen, A., \& Haberstick, B. C. (2006). The National Longitudinal Study of Adolescent to Adult Health (Add Health) twin data. Twin Research and Human Genetics, 9, 988-997.

Heatherton, T. F., Kozlowski, L. T., Frecker, R. C., \& Fagerstrom, K.-O. (1991). The Fagerström test for nicotine dependence: A revision of the Fagerstrom Tolerance Questionnaire. British Journal of Addiction, 86, 1119-1127.

Heron, J., Hickman, M., Macleod, J., \& Munafò, M. R. (2011). Characterizing patterns of smoking initiation in adolescence: Comparison of methods for dealing with missing data. Nicotine \& Tobacco Research, 13, 12661275.

Huizink, A. C., Levälahti, E., Korhonen, T., Dick, D. M., Pulkkinen, L., Rose, R. J., ... Kaprio, J. (2010). Tobacco, cannabis, and other illicit drug use among Finnish adolescent twins: Causal relationship or correlated liabilities? Journal of Studies on Alcohol and Drugs, 71, 5-14.

Johnston, L. D., O’Malley, P., Bachman, J., \& Schulenberg, J. (2013). Teen smoking continues to decline in 2013 [National press release]. University of Michigan News Service, Ann Arbor, MI, 27 pp.

Kendler, K. S., Chen, X., Dick, D., Maes, H., Gillespie, N., Neale, M. C., ... Riley, B. (2012). Recent advances in the genetic epidemiology and molecular genetics of substance use disorders. Nature Neuroscience, 15, 181-189.

Kendler, K. S., Karkowski, L., Corey, L., Prescott, C., \& Neale, M. (1999a). Genetic and environmental risk factors in the aetiology of illicit drug initiation and subsequent misuse in women. The British Journal of Psychiatry, 175, 351-356.

Kendler, K. S., Neale, M. C., MacLean, C. J., Heath, A. C., Eaves, L. J., \& Kessler, R. C. (1993). Smoking and major depression: A causal analysis. Archives of General Psychiatry, 50, 36-43.

Kendler, K. S., Neale, M., Sullivan, P., Corey, L., Gardner, C., \& Prescott, C. (1999b). A population-based twin study in women of smoking initiation and nicotine dependence. Psychological Medicine, 29, 299-308.

Kendler, K. S., Schmitt, E., Aggen, S. H., \& Prescott, C. A. (2008). Genetic and environmental influences on alcohol, caffeine, cannabis, and nicotine use from early adolescence to middle adulthood. Archives of General Psychiatry, 65, 674-682.
Koopmans, J. R., Doornen, L. J., \& Boomsma, D. I. (1997). Association between alcohol use and smoking in adolescent and young adult twins: A bivariate genetic analysis. Alcoholism: Clinical and Experimental Research, 21, 537-546.

Koopmans, J. R., Slutske, W. S., Heath, A. C., Neale, M. C., \& Boomsma, D. I. (1999). The genetics of smoking initiation and quantity smoked in Dutch adolescent and young adult twins. Behavior Genetics, 29, 383-393.

Li, M. D., Cheng, R., Ma, J. Z., \& Swan, G. E. (2003). A metaanalysis of estimated genetic and environmental effects on smoking behavior in male and female adult twins. Addiction, 98, 23-31.

Liu, J. Z., Tozzi, F., Waterworth, D. M., Pillai, S. G., Muglia, P., Middleton, L., ... Waeber, G. (2010). Meta-analysis and imputation refines the association of $15 \mathrm{q} 25$ with smoking quantity. Nature Genetics, 42, 436-440.

Maes, H. H., \& Neale, M. C. (2009). Genetic modeling of tobacco use behavior and trajectories. In G. E. Swan, T. B. Baker, L. Chassin, D. V. Conti, C. Lerman, K. A. Perkins (Eds.), NCI tobacco control monograph series 20: Phenotypes and endophenotypes: Foundations for genetic studies of nicotine use and dependence (pp. 245-288). Bethesda, MD: US Department of Health and Human Services; National Institutes of Health.

Maes, H. H., Sullivan, P. F., Bulik, C. M., Neale, M. C., Prescott, C. A., Eaves, L. J., . . Kendler, K. S. (2004). A twin study of genetic and environmental influences on tobacco initiation, regular tobacco use and nicotine dependence. Psychological Medicine, 34, 1251-1261.

Maes, H. H., Woodard, C. E., Murrelle, L., Meyer, J. M., Silberg, J. L., Hewitt, J. K., ... Carbonneau, R. (1999). Tobacco, alcohol and drug use in eight to sixteen-year-old twins: The Virginia Twin Study of Adolescent Behavioral Development. Journal of Studies on Alcohol and Drugs, 60, 293.

McGue, M., Elkins, I., \& Iacono, W. G. (2000). Genetic and environmental influences on adolescent substance use and abuse. American Journal of Medical Genetics, 96, 671677.

Morley, K. I., Lynskey, M. T., Madden, P. A., Treloar, S. A., Heath, A. C., \& Martin, N. G. (2007). Exploring the interrelationship of smoking age-at-onset, cigarette consumption and smoking persistence: Genes or environment? Psychological Medicine, 37, 1357-1367.

Munafo, M. R., Clark, T. G., Johnstone, E. C., Murphy, M. F., \& Walton, R. T. (2004). The genetic basis for smoking behavior: A systematic review and meta-analysis. Nicotine \& Tobacco Research, 6, 583-597.

Neale, M. C., Harvey, E., Maes, H. H., Sullivan, P. F., \& Kendler, K. S. (2006). Extensions to the modeling of initiation and progression: Applications to substance use and abuse. Behavior Genetics, 36, 507-524.

Öncel, S. Y., Dick, D. M., Maes, H. H., \& Alıev, F. (2014). Risk factors influencing smoking behavior: A Turkish twin study. Twin Research and Human Genetics, 17, 563-573.

RCore, T. (2012). R: A language and environment for statistical computing. Vienna, Austria: R Foundation for Statistical Computing. 
Rende, R., Slomkowski, C., McCaffery, J., Lloyd-Richardson, E. E., \& Niaura, R. (2005). A twin-sibling study of tobacco use in adolescence: Etiology of individual differences and extreme scores. Nicotine \& Tobacco Research, 7, 413419.

Saccone, N. L., Culverhouse, R. C., Schwantes-An, T.-H., Cannon, D. S., Chen, X., Cichon, S., ... Keskitalo-Vuokko, K. (2010). Multiple independent loci at chromosome 15q25. 1 affect smoking quantity: A meta-analysis and comparison with lung cancer and COPD. PLoS Genetics, 6, e1001053.

Substance Abuse and Mental Health Services Administration (SAMHSA). (2007). The OAS report: A day in the life of American adolescents: Substance use facts. Rockville, MD: Mental Health Services Administration, Office of Applied Studies.

Substance Abuse and Mental Health Services Administration (SAMHSA). (2009). Results from the 2008 national survey on drug use and health: National findings. NSDUH series H-36, HHS Publication No. SMA, 9, 4434. Rockville, MD: Mental Health Services Administration, Office of Applied Studies.

Sullivan, P. F., \& Kendler, K. S. (1999). The genetic epidemiology of smoking. Nicotine \& Tobacco Research, 1(Suppl. 2), S51-S57.
Tobacco \& Genetics Consortium. (2010). Genome-wide metaanalyses identify multiple loci associated with smoking behavior. Nature Genetics, 42, 441-447.

Unger, J. B., Lessov-Schlaggar, C. N., Pang, Z., Guo, Q., Ning, F., Gallaher, P., ... Johnson, C. A. (2011). Heritability of smoking, alcohol use, and psychological characteristics among adolescent twins in Qingdao, China. Asia-Pacific Journal of Public Health, 23, 568-580.

US Department of Health and Human Services. (1994). Preventing tobacco use among young people: A report of the Surgeon General. Washington, DC: US Department of Health and Human Services.

Vink, J. M., Willemsen, G., \& Boomsma, D. I. (2005). Heritability of smoking initiation and nicotine dependence. Behavior Genetics, 35, 397-406.

Wang, S., van der Vaart, A. D., Xu, Q., Seneviratne, C., Pomerleau, O. F., Pomerleau, C.S., ... Li, M. D. (2014). Significant associations of CHRNA2 and CHRNA6 with nicotine dependence in European-American and African-American populations. Human Genetics, 133, 575586.

Ware, J. J., van den Bree, M. B. M., \& Munafò, M. R. (2011). Association of the CHRNA5-A3-B4 gene cluster with heaviness of smoking: A meta-analysis. Nicotine \& Tobacco Research, 13, 1167-1175. 